Two other anticholinergic anti-Parkinsonian agents are currently available in Norway, biperiden and benztropine (benzhexol and procyclidine were withdrawn from the market in 1995 and 1996, respectively). The current state of knowledge concerning these other drugs is abysmal; for instance, we have not encountered comprehensive pharmacokinetic studies of any of these compounds. It is, however, notable that there are very few case reports of deaths in association with their use. No deaths, but two intoxications which required hospitalisation, have been described after intake of biperiden (Hewer \& Biedert, 1988). A total of five deaths have been reported in the literature in association with benztropine ingestion (Särnquist \& Larson, 1973; del Villar \& Liddy, 1976; Wade \& Ellenor, 1980; Catterson \& Martin, 1994). We have not found any reports of acute deaths caused by either benzhexol or procyclidine.

The data presently available show that orphenadrine is associated with a comparably high risk of acute death from overdose. In general, the use of anticholinergic agents to counter side-effects from antipsychotics should be discouraged, but if indicated, several other compounds may be used more safely. The consequences of this should be fairly obvious, but the continuum of high death rates from orphenadrine poisonings seems to demonstrate how difficult it is to change an ill-advised therapeutic tradition.

Błomquist, M., Bonnichsen, R. \& Schubert, B. (197I) Lethal orphenadrine intoxications. A report of five cases. Zeitschrift für Rechtsmedizin, 68, III.

Bosche, J. \& Mallach, H. J. (1969) Uber anatomische und chemisch toxikologische Befunde bei einer todlichen Vergiftung durch Orphenadrin. Archiv Toxikologie, 25, 76-82.

Bozza-Marubini, M., Frigerio, A., Ghezzi, R., et al (1977) Two cases of severe orphenadrine poisoning with atypical features. Acto Pharmacologica \& Toxicologica, 41 , $137-152$.

Buckdey, N. \& McManus, P. (1998) Fatal toxicity of drugs used in the treatment of psychotic illnesses. British journal of Psychiatry, 172, 461-464.

Catterson, M. L. \& Martin, R. L. (1994)

Anticholinergic toxity masquerading as neuroleptic malignant syndrome: a case report and review. Annals of Clinical Psychiatry, 4, 267-269.

Chang, T. K., Weber, G. F., Crespi, C. L., et al (1993) Differential activation of cyclophosphamide and iphosphamide by cytochrome $\mathrm{P}-4502 \mathrm{~B}$ and $3 \mathrm{~A}$ in human liver microsomes. Cancer Research, 53 , 5629-5637.

Clarke, B., Mair, J. \& Rudolf, M. (1985) Acute poisoning with orphenadrine. Lancet, i. 1386.

Cresteil, A., Monsarrat, B., Alvinerie, P., et al (1994) Taxol metabolism by human liver microsomes: identification of cytochrome P450 isoenzymes involved in its biotransformation. Concer Reseorch, 54, 386-392.

Deceuninck, F., Silverman, R. M. \& Veltman, J. G. J. (1973) Een patiente met een psychose na intoxicatie met orfenadrin. Nederiands Tijdschrift voor Geneeskünde, II7, 25-27.

Dollery, C. (ed.) (1991) Theropeutic Drugs, Vol. I. London: Churchill Livingstone.

Elenhorn, M. J. (1997) Medical Toxicology. Diognosis and Treatment of Human Poisoning. Baltimore, MD: Williams \& Wilkins.

Gjerden, P., Engelstad, K. S., Pettersen, G., et ol (1998) Dodsfall forårsket av antikolinerge antiparkinsonmedikamenter. Et nasjonalt I I-årsmateriale. Tidsskrift for den Norske Lægeforening. 118, 42-44.

Hewer, W. Biedert, S. (1988) Delirantes syndrom bei biperiden-intoxikation. Fortschritte der NeurologiePsychiatrie, 56. 133-136.

Labout, J. J. M., Thijssen, C. T., Keijser, G. G. J., et af (1982) Difference between single and multiple dose pharmacokinetics of orphenadrine hydrochloride in man. European journal of Clinical Phormocology. 2I, 343-350.

Millar, W. M. (1977) Deaths after overdoses of orphenadrine. Loncet, ii, 566.

Robinson, A. E., Holder, A.T., McDowall, R. D., et of (I977) Forensic toxicology of some orphenadrinerelated deaths. Forensic Science, 9, 53-62.

Sangster, B., van Heijst, A. N. P. \&

Zimmerman, A. N. E. (1978) Vergifting door orfenadrine. Nederlands Tijdschrift voor Geneeskünde, 122, 988-992.

Sämquist, F. Larson, C. P. (1973) Drug-induced heat stroke. Anesthesiology, 3, 348-350

del Villar, G. \& Liddy, M. (1976) Two deaths involving benztropine. Bulletin of the International Association of Forensic Toxicologists, 12, $11-12$.

Wade, L. C. Elenor, G. L. (1980) Combination of mesoridazine and benztropin mesylate induced paralytic ileus. Two case reports. Drug intelligence and Clinicol Pharmocy, 14, 17-22.

Wilkinson, L. G., Thomson, B. M. \& Pannell, L. K. (1983) A report on the analysis of orphenadrine in post mortem specimens. Journal of Analytical Toxicology, 7 , $72-75$.

Lars Slerdal Department of Pharmacology and Toxicology, Norwegian University of Science and Technology, N-7005 Trondheim, Norway

Pal Gjerden Department of Psychiatry, Telemark Central Hospital, N-3710 Skien, Norway

\section{The beginning and end of psychiatric pathways}

Sir: The article by Lincoln et al (1998) made an interesting reading. The understanding of contacts that people make prior to consulting a psychiatrist is a vital factor in planning to reduce the delays in seeking treatment. Based on the results of a multicentre study conducted in India (further details available from the author upon request) with a similar background, we would like to share our experiences.

Elucidating responses on various aspects of the pathways to care may lead to responder bias in the case of patients who are psychotically unstable or with a history of primary memory disorders like amnesia and dementia. Moreover, cross-checking statements from the accompanying key informants or relatives would have enhanced the accuracy of the collected data.

Our study consisted of 396 subjects selected from five geographically and culturally different regions of India. The diagnostic make-up of our sample revealed that a majority of people suffering from either schizophrenia $(53.7 \%)$ or depression $(53.5 \%)$ had reached a psychiatrist within a year of onset of symptoms, whereas the group suffering from either acute transient psychosis, substance-related psychosis or other unspecific psychosis reached a psychiatrist much earlier (more than $50 \%$ within one month). Although it is difficult to explain this variation, it could be due to the relatively benign prodromal phases of depression and schizophrenia compared with the other group. So far as the first care-givers are concerned, we found that psychiatrists were consulted in $33.7 \%$ of the cases which is much higher than that reported by Lincoln et al $(16.1 \%)$.

Finally, it is not clear where exactly the pathways to psychiatric care begin. Do they begin with the family, friends or the patient himself or herself? A similar question remains regarding its end. Does it really end with the psychiatrist? In our study we found that $1-2 \%$ of study subjects in different centres consulted further care-givers even after seeing a psychiatrist. Hence, we hypothesise that pathways to psychiatric care are not static events or strategies, but an ongoing process in search of an ideal care-giver. It is a process dependant on a wide range of biopsychosocial factors which need to be understood individually.

Lincoln, C., Harrigan, S. A McGorry, P. D. (1998) Understanding the topography of early psychosis pathways. An opportunity to reduce delays in treatment. British journal of Psychiatry, 172 (suppl. 33), 2l-25.

\section{S. C. Pradhan, M. Meghachandra}

Singh Institute of Human Behaviour and Allied Sciences, G. T. Road, Post-Jhilmil, Dilshad Garden, Delhi-I10 095, India 